\title{
Kidney Manifestations of Inflammatory Bowel Diseases
}

\author{
Kawthar Braysh'1, Alice Gerges Geagea1, Charbel Matar², Manfredi Rizzo ${ }^{3}$, Assaad Eid", \\ Liliane Massaad-Massade ${ }^{4}$, Samir Mallat ${ }^{2 *}$, Abdo Jurjus ${ }^{1 *}$
}

\author{
${ }^{1}$ Department of Anatomy, Cell Biology and Physiological Sciences, Faculty of Medicine, American University of Beirut (AUB), \\ Beirut, Lebanon \\ ${ }^{2}$ Department of Internal Medicine, American University of Beirut Medical Center (AUBMC), Beirut, Lebanon \\ ${ }^{3}$ Department of Internal Medicine, University of Palermo, Palermo, Italy \\ ${ }^{4}$ Vectorology and Anticancer Therapies, UMR 8203 CNRS, Université Paris-Sud, Gustave Roussy, Université Paris-Saclay, \\ Villejuif, France \\ Email: *aj00@aub.edu.lb, *sm104@aub.edu.lb
}

How to cite this paper: Braysh, K., Geagea, A.G., Matar, C., Rizzo, M., Eid, A., Massaad-Massade, L., Mallat, S. and Jurjus, A. (2018) Kidney Manifestations of Inflammatory Bowel Diseases. Open Journal of Gastroenterology, 8, 172-191.

https://doi.org/10.4236/ojgas.2018.85020

Received: February 22, 2018

Accepted: May 27, 2018

Published: May 30, 2018

Copyright $\odot 2018$ by authors and Scientific Research Publishing Inc. This work is licensed under the Creative Commons Attribution International License (CC BY 4.0).

http://creativecommons.org/licenses/by/4.0/

\begin{abstract}
Inflammatory bowel disease (IBD) is profoundly associated with extraintestinal manifestations (EIM) that can involve almost every organ in our body. Although the exact etiology of IBD is still poorly understood, it is generally characterized by an overly aggressive inflammatory response in the intestinal mucosa. Renal damage is one of the manifestations encountered in Crohn's disease (CD) and ulcerative colitis (UC) and it accounts for $4 \%-23 \%$ of IBD patients. The common renal complications of IBD include: glomerulonephritis, tubulointerstitial nephritis, nephrolithiasis, amyloidosis and iatrogenic complications of IBD treatment. Several hypotheses have emerged to explain the pathogenic mechanisms underlying the prevalence of IBD-induced kidney injuries. The present work aims to elucidate the pathological principles that drive secondary renal injury in individuals with IBD and highlight the currently used therapeutic strategies for evaluating, monitoring and treating kidney complications-related IBD.
\end{abstract}

\section{Keywords}

IBD, Crohn's Disease, Ulcerative Colitis, Inflammatory Cytokines, Kidney Diseases

\section{Introduction}

Inflammatory bowel disease (IBD) is an idiopathic disease characterized by severe inflammation of the gastrointestinal tract. It encompasses two major clini- 
cal entities: ulcerative colitis (UC) and Crohn's disease (CD) [1]. Although, the exact etiology in IBD remains uncertain, it is generally caused by an immunological imbalance in the intestinal mucosa, which is often mediated by an inappropriate and sustained inflammatory response against environmental factors and commensal pathogens in genetically susceptible hosts [2]. IBD is profoundly associated with extraintestinal manifestations (EIM) that have become more frequently diagnosed among patients with CD or UC. Renal complication is considered as one of the EIMs and accounts for $4 \%-23 \%$ of IBD patients [3]. The most commonly encountered renal diseases in patients with IBD are: glomerulonephritis, tubulointerstitial nephritis, nephrolithiasis and amyloidosis (see Table 1) [4]. The association of kidney diseases with IBD has been reported in many clinical and experimental studies; however, the underlying mechanism(s) are not fully elucidated. Several hypotheses have been postulated to explore the nature of this involvement whether kidney injury occurs as a secondary complication to IBD, shares the same patho-immunological origin, is an autoimmune disease by itself, or it is provoked as side-effect to therapy.

The present work aims to elucidate the pathological mechanisms that drive secondary renal complications in individuals with IBD and highlight the required surveillance of kidney complications associated with IBD.

\section{Pathophysiological Principles of IBD}

The pathogenesis of IBD is mainly influenced by disrupted intestinal immunological homeostasis and deregulated interaction with the commensal microbiota in genetically susceptible hosts. The traditionally accepted paradigm indicates

Table 1. Kidney manifestations in IBD.

\begin{tabular}{c}
\hline Renal manifestations in IBD \\
Glomerulonephritis \\
IgA nephropathy \\
IgM nephropathy \\
Mesangioprolifarative nephristis \\
Membranous nephropathy \\
Anti-GBM nephritis \\
Tubulointerstitial nephritis \\
Interstitial nephritis \\
Granulamous interstitial nephritis \\
Nephrolithiasis \\
Hyperoxaluria \\
Uric acid stones formation \\
Renal Amyloidosis \\
Renal iatrogenic complications \\
Aminosalicylates \\
TNF- $\alpha$ inhibitors \\
Calcineurin inhibitors (Cyclosporin and Tacrolimus)
\end{tabular}


that IBD is governed by overly aggressive cells of the acquired immune system. Despite the common clinical symptoms that occur in both CD and UC, the two diseases are shown to display distinct immunological phenotypes. CDs are generally ruled by $\mathrm{T}$ helper (Th) 1-associated cytokines such as Interferon gamma (IFN- $\gamma$ ), tumor necrosis factor alpha (TNF- $\alpha$ ), IL-12 and IL-18, whereas Th2-related cytokines such as IL-4, IL-5 and IL-13 are increased in the lamina propria of UC patients (see Figure 1) [5] [6] [7]. However, this situation could not be mutually exclusive. It has interestingly been shown that the induction stage and the perpetuation of chronic phase display diverse and mixed immunological mechanisms. Rivera-Nieves $\mathrm{J}$ et al. have demonstrated, using SAMP1/YiTFC mice model which develop ileitis but not colitis, that Th1 polarized cells were activated during the onset of the disease, while Th1/Th2 pattern is detected later during the chronic inflammation, suggesting that the immunological profile is highly dependent on the stage on the disease [8].

Given the complexity of the disease, the diverse clinical response to therapeutic agents emphasizes that there are still unexplored signaling mechanistic pathways involved in IBD pathogenesis. Recent studies have described the crucial role of Th17 cells, a subset of naive T cells, in IBD [9]. The growth and differentiation of Th17 is mediated by the presence of particular cytokines within the inflammatory environment including IL-6, IL-1 $\beta$ and IL-23 [10]. Th17 cells release
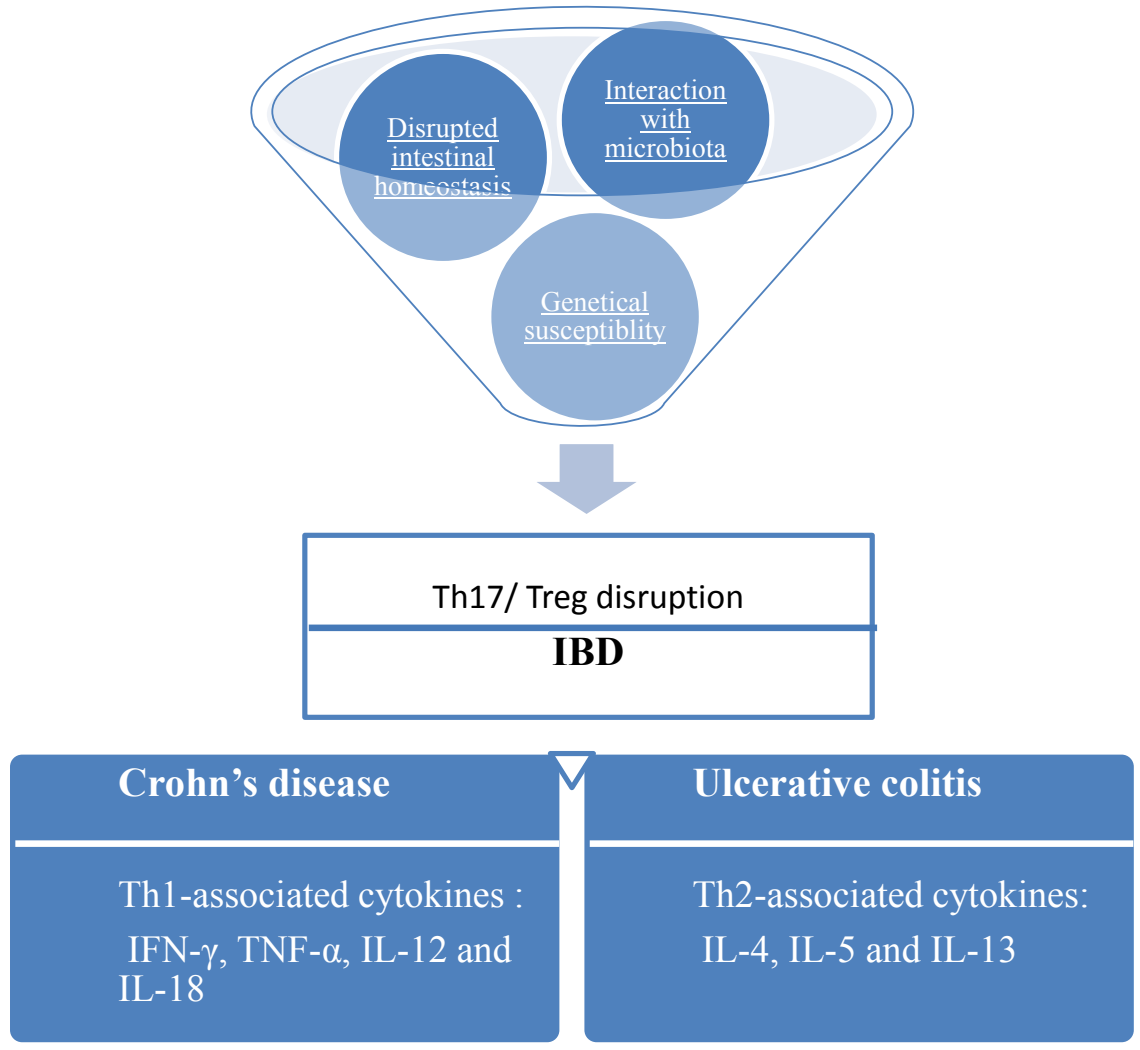

Impaired activity of anti-inflammatory cytokines: IL-10 and TGF- $\beta$

Figure 1. Pathophysiological principles of IBD. 
cytokines such as IL-17and IL-22 [11], whose expression is enhanced in CD and UC patients [12]. On the other side, regulatory T cells (Treg) are known as essential players in immune tolerance and suppression of excessive inflammation. Although Th17 and Treg have opposing functions, their differentiation is regulated by shared mechanisms and common cytokines such as TGF- $\beta$. Thus, the decision to differentiate into either Th17 or Treg depends greatly on integrated environmental stimuli and cytokine-regulated balance of these cells [13]. The disruption in Th17/Treg balance is profoundly associated with the development of IBD. However, the mechanism is not fully understood. Dysbiosis is considered as a key factor to affect Treg/Th17 axis in IBD patients [13]. Moreover, recent findings have revealed the equal importance of the innate immune system and intestinal epithelium in the pathogenesis of IBD [2]. CD associated -Nod2 gene polymorphisms have emerged as evidence linking the role of innate response in disease development [14]. Normally, Nod2 acts as an intracellular receptor to sense bacterial cell wall components and trigger the innate immune system via pro-inflammatory pathways activation. Loss of Nod 2 function through mutation is associated with primary failure to pathogen infection, defective cytokine response and subsequent aberrant inflammation [15].

In addition to the pro-inflammatory cytokines that assist in the development of chronic inflammatory diseases, the impaired activity of anti-inflammatory cytokines such as IL-10 and TGF- $\beta$ is also implicated in IBD pathogenesis. The IL-10 family consists of a panel of anti-inflammatory cytokines that are expressed by the adaptive and innate immune cells. They block antigen representing cells and inhibit the release of pro-inflammatory cytokines. Most of the therapeutic approaches of IBD were tested in IL-10 knockout animals, since it provides a good IBD model that closely resembles human IBD [16]. In fact, IL-10 gene mutations are strongly associated with UC [17], however, in the inflamed mucosa and granulomas of $\mathrm{CD}$, its expression is reduced. This reduction is associated with increased production of the pro-inflammatory IL-12 and IFN- $\gamma$ [18] which are known to mediate activated mucosal $\mathrm{T}$ cell to survive apoptosis, another mechanism of IBD pathogenesis. In addition, TGF- $\beta$ is another inhibitory cytokine that regulates the immune response. Despite its conflicting role, TGF- $\beta$ expression is upregulated in CD and UC [19] [20], however, its signaling activity appears to be defective in induced colitis [19].

\section{Glomerulonephritis (GN)}

Glomerulonephritis is a type of kidney inflammation affecting the glomeruli and small blood vessels in kidneys. The histological patterns of glomerulonephritis vary and include IgA nephropathy, IgM nephropathy, mesangioprolifarative nephritis, membranous nephropathy and anti-glomerular basement membrane nephritis [21] [22]. IgA Nephropathy (IgAN) is the most common and has a significantly higher diagnostic prevalence in IBD patients than non-IBD [23]. IgAN is characterized by elevated levels of serum $\operatorname{IgA}$ with mesangial deposition. Patients with IgAN often develop proteinuria and hematuria with deterioration of 
renal function. Recent clinical studies have demonstrated that IgAN appears concurrently with the onset or exacerbation of IBD, mainly CD [23] [24]. However, the connection between the impaired mucosal immunity and the progression of IgAN is still unclear. Clinical findings demonstrated that the high levels of systematic IgA derived from the ileum tract leads to onset of IgA nephropathy. Given its importance in the mucosal immune defense against microbial and environmental antigen, IgA disposition in the mesangium is likely to be associated with loss of immune exclusion, chronic immune stimulation, and mucosal inflammation leading to IgAN [25]. Additionally, successful treatment of IBD using immunosuppressants was associated with clinical remission of kidney damage [4], suggesting a common pathogenic mechanism linking the two diseases. It has also been indicated that the imbalance between Th17/Treg and the increase of renal tubular IL-17 play a significant role in (idiopathic) IgAN progression in patients without IBD. This imbalance was associated with declined renal function, proteinuria, and severe tubulointerstitial damage. In the same line, Choi JY et al. have reported that both renal and ulcerated colonic tissues were positively immunostained for IL-17. However, IL-17 was absent in renal tissue with primary IgAN. These findings suggest the simultaneous involvement of IL-17 in both worsening intestinal inflammation and enhancing rapidly progressive IgAN development in CD patients [24]. Interestingly, wang J et al. have revealed in their experimental studies the etiology behind IgAN in IBD patients, highlighting the critical role of LIGHT, a TNF- $\alpha$ super family member and keystone mediator in the pathogenesis of CD [26] [27]. By establishing a LIGHT transgenic mice model, Wang J. and his group have shown that secondary IgAN is initiated by severe $\mathrm{T}$ cells associated-intestinal inflammation causing an overproduction, impaired transportation and clearance of serum IgA. This cascade of events will subsequently lead to elevated serum IgA and consequently glomerular IgA deposition [27]. Genetic linkage between secondary IgAN and IBD has also been reported and the direct association of HLA-DQ/DR has been described in both diseases [21] [28] [29] [30].

In this context, Pozzi $\mathrm{C}$ et al. showed the effectiveness of corticosteroids treatment in IgAN patients. The results of their randomized, controlled trial, demonstrated that a 6-month steroid treatment is able to reduce proteinuria levels and stabilize renal function for over a long time [31]. The beneficial effect of steroid treatment was further supported by several clinical reports of IBD-related IgAN cases, suggesting that the early discontinuation of IBD drugs supplemented by steroid treatment resulted in complete remission of bowel disease, reduction of serum levels of IgA and improvement of renal impairment [31].

\section{Tubulointerstitial Nephritis}

Tubulointerstitial nephritis (TIN) is considered as the second most common diagnosis in IBD [23] [32] [33]. Kidney tubular markers are usually used as predictors to detect early renal deterioration in IBD, including Alpha-1-microglobulin 
$(\alpha 1$-MG), $\quad \mathrm{N}$-acetyl- $\beta$-d-glycosaminidase $\quad(\beta$-NAG), and $\beta 2$-microglobulin ( $\beta 2$-MG). These low molecular weight proteins are normally filtered by the glomerulus in healthy kidneys, and reabsorbed in the proximal tubules. Their presence in urine reflects sub-clinical tubular damage. Many clinical findings depicted the concomitant presence of interstitial nephritis (IN) and IBD in both $\mathrm{CD}$ and UC cases as well as the etiology behind it, whether it is drug induced-nephrotoxicity or extra manifestation of IBD, has been extensively addressed in the literature. Several case studies reported TIN in IBD patients as drug induced nephrotoxicity, more particularly in patients treated with 5-Aminosalycilic Acid (5-ASA) or its derivatives such as mesalamine and sulfasalazine [34] [35]. Others proposed that the concurrent development of TIN in treatment-naive CD patients or after discontinuation of IBD drug therapy confirms that TIN could be an IBD-related kidney complication [36] [37] [38] [39]. A recent retrospective study by Ambruzs JM et al. showed that granulomatous IN is caused by a cell-mediated hypersensitivity reaction, while renal tubular damage seen in IBD patients, that is often associated with proteinuria, is directly correlated to disease activity instead of therapy [23]. Moreover, positive correlation between urine tubular proteins and disease activity has been suggested. Fraser JS et al. reported that $\beta$-NAG and $\alpha 1$-MG were increased in $48 \%$ and $52 \%$ patients, respectively, at diagnosis. However, it was demonstrated that the commencement of 5-ASA was not associated with significant changes in urinary protein excretion [40]. Kreisel W. et al. have shown that elevated $\beta$-NAG is exclusively found in patients with active UC, thus excluding the toxic side effect of 5-ASA and sulphasalazine [41]. Similarly, Herrlinger KR et al. demonstrated that the levels of $\alpha 1-\mathrm{MG}$ is highly correlated with bowel disease activity in both $\mathrm{CD}$ and UC patients with no significant influence of 5-ASA [37].

The underlying pathologic mechanism linking both diseases remained unclear. Poulou et al., have shown the deleterious role of TNF- $\alpha$ in enhancing a systematic inflammatory response by demonstrating a positive relationship between tubular microproteinuria and high serum levels of TNF- $\alpha$ [42]. TNF- $\alpha$ is also shown to contribute to protein leakage and tissue damage through disrupting the endothelium glycocalyx [43]. Ranganathan P et al. have examined role of Netrin-1 and laminin related-protein, in the suppression of acute kidney injury in a Dextran Sulfate Sodium (DSS) induced-colitis animal model [44]. Data showed that, over expression of Netrin-1 on proximal tubular cells was able to reduce the expression and the activity of IL-16, which is known to stimulate the release of pro-inflammatory cytokines such IL-6, IL-1 $\beta$, IL-15 and TNF- $\alpha$ [45] and consequently, it could inhibit neutrophils infiltration.

Early discontinuation of 5-ASA supplemented by corticosteroid therapy could be beneficial for the treatment of IBD with TIN [34] [42]. Recent studies showed that infliximab (anti-TGF- $\alpha$ inhibitor) is able to improve intestinal and TIN symptoms in initially presented CD [36], Moreover, regular measuring of serum creatinine is greatly recommended to monitor renal function in IBD (see Table 2). 
Table 2. Tubulointerstitial nephritis in IBD.

\begin{tabular}{|c|c|c|}
\hline \multicolumn{3}{|c|}{ Tubulointerstitial nephritis in IBD } \\
\hline Type & Description & Clinical Management \\
\hline $\begin{array}{l}\text { Drug-related } \\
\text { nephrotoxicity }\end{array}$ & $\begin{array}{l}\text { - Aminosalicylate and anti-TNF } \\
\alpha \text {-induced nephropathy } \\
\text { - } \text { The incidence is one case per } 4000 \\
\text { patients/years who received 5-AZA } \\
\text { - Early detection of 5-AZA associated } \\
\text { IN (<12 months) responds } \\
\text { completely to drug withdrawal }\end{array}$ & $\begin{array}{l}\text { Monitoring of kidney function by } \\
\text { measuring: } \\
\text { GFR } \\
\text { Serum creatinine levels } \\
\text { Urinary Levels of tubular markers }\end{array}$ \\
\hline EIM of IBD & $\begin{array}{ll}\text { - } & \text { Not related to IBD } \\
\text { drugs-nephrotoxicity } \\
\text { - } & \text { Occurrence in treatment-naive IBD } \\
\text { patients or after drug } \\
\text { discontinuation } \\
\text { - } & \text { Early discontinuation of 5-ASA } \\
\text { supplemented by corticosteroid } \\
\text { therapy is beneficial }\end{array}$ & $\begin{array}{l}\text { ( } \alpha 1-M G, \beta-N A G, \beta 2-M G) \\
\text { Assessment of serum creatinine of IBD } \\
\text { patients prior to commencing drug } \\
\text { therapy, monthly for the first } 3 \text { months, } 3 \\
\text { monthly for the remainder of the year and } \\
\text { then annually thereafter }\end{array}$ \\
\hline
\end{tabular}

\section{Nephrolithiasis}

Patients with IBD, both CD and UC, are at high risk for the development of renal stones. The prevalence of nephrolithiasis is higher in IBD patients (12\% to $28 \%$ ) than the general population [4] [46]. The mechanism of stones formation seems to be different in $\mathrm{CD}$ and UC patients. Severe disease activities, with long duration (8 - 10 years), that are usually accompanied by severe diarrhea, steatorrhea and bile salt malabsorption, are considered as major risk factors for the development of renal stones in CD patients [47]. Another study on UC patients who had J-pouch panproctocolectomy showed that the presence of several EIMs and low serum bicarbonate level are the most important risk factors for the presence of concurrent nephrolithiasis [48].

Renal stones or calculi in IBD patients are composed either of uric acid or calcium oxalate. Hyperoxaluria by definition is as an excessive oxalate urinary execretion. Clinical studies show that enteric hyperoxaluria (greater than 48 $\mathrm{mg} / 24 \mathrm{hr}$ ) is more prevalent in CD than in UC [3] [49]. Many findings have demonstrated that $\mathrm{CD}$ patients who have undergone surgical procedures such as ileocecal resection, intestine bypass and total colectomy, are at higher risk to develop secondary hyperoxaluria [47]. The mechanism of hyperoxaluria appears to be multifactorial. The high levels of non-absorbed fatty acids, present in diseased or resected distal ileum, bind to calcium and imped its bioavailability. The low amount of luminal calcium in gut enhances high concentrations of soluble oxalate and increased oxalate absorption that eventually diffuse into the blood and then to kidneys [50]. Also, the high concentrations of bile acids and colonic inflammation enhance colonic permeability to oxalate, resulting in passive paracellular absorption of oxalate [50]. Another proposed mechanism is related to decolonization of Oxalobacter formigenes bacterium that causes reduction in oxalate catabolism. Nonetheless, UC patients are more susceptible to the devel- 
opment of uric acid stone. In UC, especially after ileostomy, loss of alkaline fluids in liquid stool causes metabolic acidosis that is accompanied with low urinary volume and $\mathrm{PH}$, a situation which subsequently leads to uric acid super-saturation. Urinary excretion of crystallization inhibitors such as citrate and magnesium may also be considerable factor of uric stones formation [51].

Furthermore, hyperoxaluria has the potential to cause devastating consequences on kidneys. Nazzal L et al., have shown that CD patients, diagnosed with enteric hyperoxaluria, develop progressive chronic kidney diseases (CKD), eventually leading to ESRD [50]. Renal histological examination depicts marked interstitial inflammation and fibrosis as well as cortical changes that include glomerular sclerosis and tubular atrophy [52]. In addition, oxalate crystals can cause tubular cell damage through stimulating innate immunity. Renal epithelial cells, in turn, synthesize a variety of chemoattractants and cytokines that interface with inflammatory cells [53]. This disruption of immunological homeostasis will eventually lead to the progression of crystal-associated interstitial fibrosis and CKD [54]. It was also demonstrated that exposure to oxalate induces toxic responses that affect renal epithelial cells. These responses include altered mitochondrial function and gene expression, generation of reactive oxygen species and reduction in cell viability [53].

On the other hands, Rodgers AL et al. have assessed different preventive strategies for the treatment of nephrolithiasis in IBD patients. They found out that calcium supplements could help reduce stone risk in patients with severe enteric hyperoxaluria, however, they also suggested that initial efforts should be directed toward reducing urinary oxalate by reducing dietary oxalate [55]. Urine alkalization and citrate therapy that increases both urine $\mathrm{pH}$ and urinary citrate can provide an additional therapeutic benefit for UC patients, more particularly those receiving aminosalicylates [56]. Increased water intake and regular monitoring with regular urinalysis and proper imaging of the upper tract should always be considered in all IBD patients (see Table 3).

Table 3. Nephrolithiasis in IBD.

\begin{tabular}{|c|c|c|c|}
\hline \multicolumn{4}{|c|}{ Nephrolithiasis in IBD } \\
\hline $\begin{array}{c}\text { IBD-associated } \\
\text { disease }\end{array}$ & $\begin{array}{l}\text { Clinical } \\
\text { diagnosis }\end{array}$ & Pathological conditions & Clinical management \\
\hline$C D$ & Hyperoxuloria & $\begin{array}{l}\text { - } \\
\text { - } \\
\text { Increased salt malabsortion } \\
\text { permeability } \\
\text { - Decolonization of } \\
\text { Oxalobacter formigenes }\end{array}$ & $\begin{array}{l}\text { Calcium supplementation } \\
\text { Dietary oxalate reduction } \\
\text { Pyridoxine (B6) to decrease oxalate } \\
\text { synthesis }[3] \\
\text { Citrate and magnesium } \\
\text { supplementation } \\
\text { (in case of recurrence) }[3]\end{array}$ \\
\hline$U C$ & $\begin{array}{c}\text { Uric acid - } \\
\text { supersaturation - }\end{array}$ & $\begin{array}{l}\text { - Low urinary vloume } \\
\text { - Low } P H\end{array}$ & $\begin{array}{l}\text { Diarrhea therapy } \\
\text { Urine alkalization } \\
\text { Increased fluid intake } \\
\text { Citrate and magnesium } \\
\text { supplementation }\end{array}$ \\
\hline
\end{tabular}




\section{Renal Amyloidosis}

Renal amyloidosis is a rare but serious renal complication that may occur in IBD patients, more frequently among patients with $\mathrm{CD}$ [57]. It usually manifests itself by proteinuria and renal insufficiency. Patients with advanced renal amyloidosis may require dialysis or transplantation [57]. It has been shown that AA amyloid nephropathy is considered as an early complication in $\mathrm{CD}$, with the absence of clinical symptoms [58].

Several inflammatory mediators are associated with the increase of serum amyloid A (SAA) synthesis [59]. For instance, IL-1 is considered as a potent inducer of SAA [60]. It has been shown that the anti-IL-1 treatment was able to ameliorate proteinuria, control inflammation and prevent further amyloid accumulation in autoimmune-associated amyloidosis [61]. Other findings have indicated the beneficial effect of TNF- $\alpha$ inhibitory drugs in treating amyloidosis secondary to CD. The anti-TNF- $\alpha$ agents, more particularly infliximab, has been shown to act through two different mechanisms; first it reduces SAA synthesis mediated by TNF- $\alpha$ and IL- 6 and, thereby, reduces amyloid deposition. Second, it decreases glomerular inflammation and albuminuria that are induced by the same cytokines [57] [58]. These findings suggest that the early diagnosis of the association of amyloidosis and CD would improve prognosis in patients.

\section{Renal Iatrogenic Complications of IBD Treatment}

The ultimate therapeutic goals in IBD are mucosal healing, inducing and maintaining long-term remission and decreasing the risk of cancer development. Although several drugs have been considered beneficial for the treatment of IBD, their renal adverse effect has been well debated. These drugs include aminosalicylates, TNF- $\alpha$ inhibitors and calcineurin inhibitors (See Table 4).

\section{Aminosalicylates}

Aminosalicylates have been used as first-line treatment of IBD patients. Studies have shown that aminosalicylates are effective in enhancing and maintaining a long-term remission in UC patients. They are also shown to be effective in treating mild to moderate CDs. Aminosalicylates are chemically derived from Sulfasalazine that is split by intestinal bacteria into sulphapyridine and 5-aminosalicylic acid (5-ASA). A randomized controlled trial conducted in 1977, showed that 5-ASA is the active therapeutic moiety of Sulfasalazine [62]. To date, various formulations of 5-ASA have been developed providing effective treatment for IBD, often at high doses, without the toxic effects attributed to the sulfapyridine moiety of sulfasalazine. 5-ASA mediates its anti-inflammatory role through various mechanisms of action. It has been hypothesized that 5-ASA activates PPAR-gamma which in turn transrepresses key inflammatory response genes such as NFK-B [63]. 5-ASA is also known to inhibit IL-1, IL-2 and TNF- $\alpha$ and acts as a potent antioxidant and free-radical scavenger [64]. An increasing number of reports focused on renal damaged associated with mesalazine therapy 
Table 4. Renal iatrogenic complications of IBD Treatment:

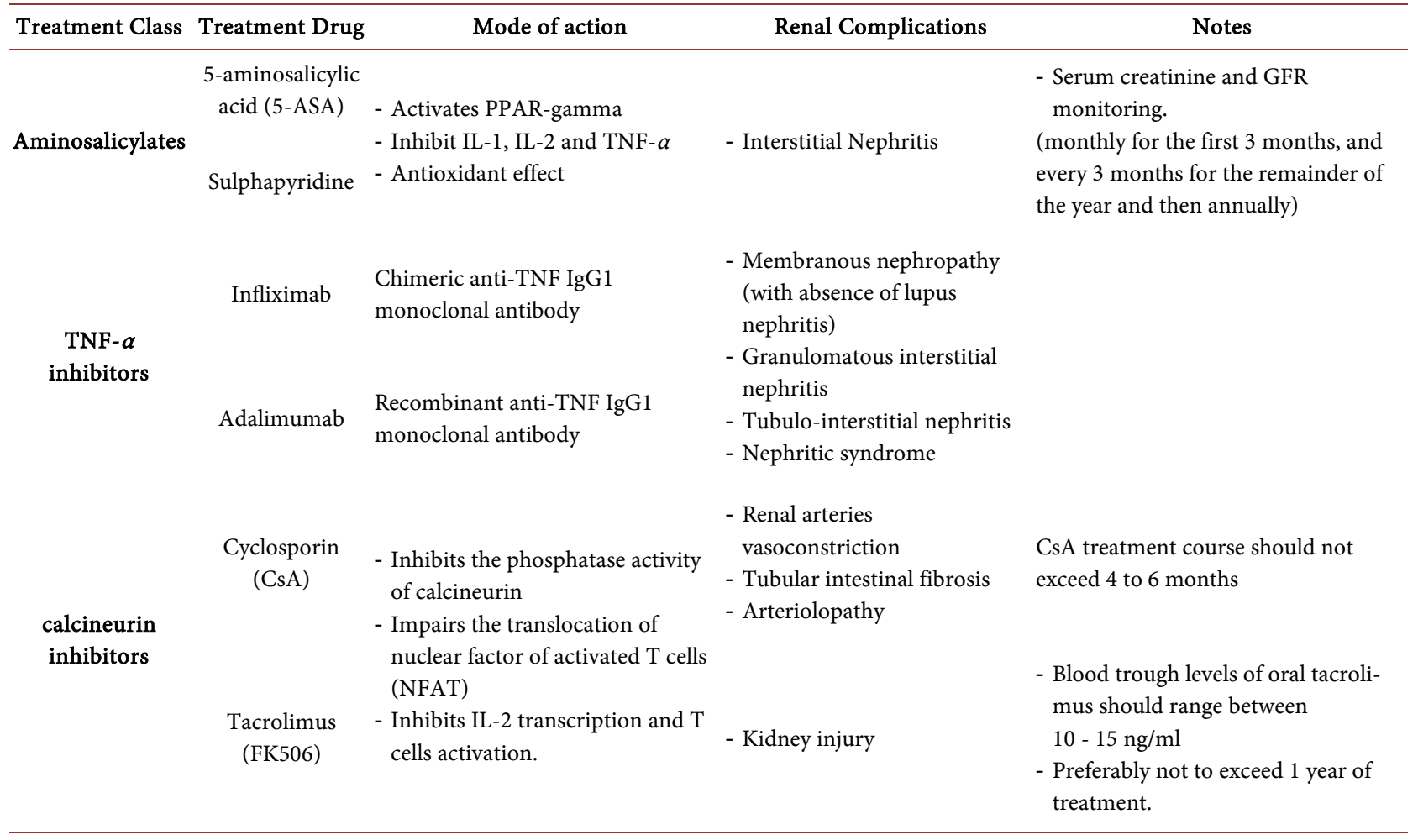

in IBD patients, in which chronic IN is recognized as a major complication. Previous findings suggested that IN occurs in less than 1 in 500 patients [65]. Ransford et al. evaluated the adverse reaction reported to the Committee on Safety of Medicine and revealed an increased risk of IN accounted for 11.1 cases per million prescriptions of mesalazine [66]. A huge prospective and retrospective study conducted in United Kingdom showed that the incidence of 5-ASA associated-nephrotoxicity among IBD's is approximately one case per 4000 patients/years [67]. Although the incidence of severe renal injuries is low, the morbidity in affected individuals is significantly very high and may progress to ESRD. Renal function improvement depends on IN detection and therapy duration before drug cessation. World $\mathrm{M}$ et al. have shown that early detection of IN, within 10 months of mesalazine therapy initiation, responds completely to drug withdrawal and restoration of renal function could be achieved [65]. On the other hand, a delayed diagnosis leads to a partial recovery of serum creatinine upon drug withdrawal [67]. Muller et al. indicated that there is no significant correlation between drug dosage or treatment duration and degree of renal impairment [64] [67], in contrary to previous studies that illustrated the association of renal dysfunction with high doses ( $>3 \mathrm{~g} /$ day) [68]. The risk of 5-ASA side effect on kidneys appears to be dose independent.

Studies have considered that serum creatinine and glomerular filtration rate (GFR) measurements are the most reliable tests to predict drug nephrotoxicity. The assessment of urinary proteins is not preferable since tubular proteinuria can occur as result of extra manifestation of IBD regardless of 5-ASA treatment. 
Regular monitoring of renal function is recommended for earlier detection. Assessment of serum creatinine should be performed in patients prior to commencing drug therapy, monthly for the first 3 months, and every 3 months for the remainder of the year and then annually, thereafter [65] [69] [70].

\section{TNF- $\alpha$ Inhibitors}

TNF- $\alpha$ inhibitors have a beneficial role in the treatment of several autoimmune diseases such as IBD, rheumatoid arthritis, psoriatic arthritis, juvenile idiopathic arthritis and ankylosing spondylitis. The anti-TNF monoclonal antibodies including infliximab (chimeric anti-TNF IgG1 monoclonal antibody) and adalimumab (recombinant anti-TNF IgG1 monoclonal antibody) are effective in the treatment of moderate to severely active IBD patients through promoting mucosal healing and inducing long-term remission. They are also known to be effective in treating renal amyloidosis secondary to crohn's disease as well as GN [71] [72].

The use of TNF- $\alpha$ inhibitors has been associated with induction of autoimmune diseases such as systemic lupus erythematosus, systemic vasculitis and sarcoidosis [73]. The occurrence of renal damage also appears plausible. Several cases of membranous nephropathy (with absence of lupus nephritis), granulomatous interstitial nephritis and tubulointerstitial nephristis have been reported after anti- TNF- $\alpha$ therapy [74] [75] [76] [77]. Dumitrescu G et al. recently reported a case of UC patient who developed nephritic syndrome after infliximab infusion. This was associated with biopsy proven-focal glomerulosclerosis and acute tubular sclerosis [78].

The possible mechanism is binding of anti TNF- $\alpha$ to their antigen that is often present on visceral epithelial cells and on sub-epithelial deposit in membraneous nephropathy, leading to apoptotic cell death [79]. Moreover, TNF- $\alpha$ inhibitors can also induce anti-nuclear antibodies (ANA) and anti-DNA antibodies (Anti-ds-DNA) giving rise to either lupus-like immune complex GN or anti-neutrophil cytoplasmic antibody-related necrotizing and crescentic GN in susceptible individuals [79] [80].

\section{Calcineurin Inhibitors}

Cyclosporin (CsA) and tacrolimus are calcineurin inhibitors indicated as second-line therapy of severely active IBD. Although they differ in their molecular structure and intercellular binding characteristics, both drugs exert their immunosuppressive role through inhibiting the phosphatase activity of calcineurin, impairing the translocation of nuclear factor of activated $\mathrm{T}$ cells (NFAT) and, thereby, inhibiting IL-2 transcription and T cells activation. The therapeutic efficacy of calcineurin inhibitors is often limited by their severe renal adverse effect.

\section{Cyclosporin (CsA)}

Two major categories of nephrotoxicity have been linked to CsA treatment: the 
acute and chronic renal injuries. The acute renal damage is characterized by vasoconstriction that is enhanced by impaired release of vasoconstrictors and results in increased serum creatinine, dramatic reduction in GFR and renal dysfunction [81]. This vasoconstriction is usually mediated by endothelin, thromboxane, angiotensin II, reduction of prostacyclin and nitric oxide [82]. Acute injury is often reversed upon drug discontinuation. On the other hand, chronic renal injury is characterized by vasoconstriction and structural lesions that are associated with irreversible tubular intestinal fibrosis and arteriolopathy [83] [84]. The factors implicated in chronic CsA nephrotoxicity are renin-angiotensin-aldosterone system and renal hypoxia [85]. Chronic CsA nephrotoxicity is irreversible and often progresses to ESRD. Furthermore, CsA mediated-nephrotoxicity depends on the dose and duration of the treatment [86]. Although drug efficacy is established in active IBD at higher doses, it has been shown that mild nephrotoxicity occurs in uncontrolled trials of low doses of CsA ( $\leq 5 \mathrm{mg} / \mathrm{kg} /$ day), while there is $\geq 20 \%$ risk of nephropathy (interstitial fibrosis, tubular atrophy and arteriolopathy) in IBD patients treated with high doses ( $>5$ $\mathrm{mg} / \mathrm{kg} /$ day) [87] [88] [89]. The total duration of CsA treatment should not exceed 4 to 6 months, and treatment using another remission maintenance drug should be initiated [90].

\section{Tacrolimus}

Tacrolimus (FK506), an immunosuppressive drug, was initially used to inhibit transplantation rejection. It is also used as a remission-induction therapy in refractory IBD. Studies have demonstrated that the optimal blood trough levels of oral tacrolimus after 2 weeks treatment ranged between $10-15 \mathrm{ng} / \mathrm{ml}$ [91]. The incidence of nephrotoxicity significantly increased when the whole blood concentration of tacrolimus exceeded $20 \mathrm{ng} / \mathrm{ml}$ [92]. Ogata $\mathrm{H}$ et al., have reported an increase of serum creatinine (30\% above baseline) in $14.8 \%$ of UC patients after 10 weeks of oral tacrolimus administration (reaching blood trough levels of $8.8 \mathrm{ng} / \mathrm{ml}$ at week 10) [91]. Similarly, Sandborn WJ et al., reported an increase in serum creatinine in $38 \%$ of CD patients treated with tacrolimus $(0.2 \mathrm{mg} / \mathrm{kg} / \mathrm{day}$ for 10 weeks), that was successfully managed by dose reduction [93]. Tacrolimus appears to be effective in treating pediatric refractory bowel disease; however, long-term treatment (more than 1 year) was associated with irreversible renal injury [94]. Asada A et al., have demonstrated the correlation between CYP3A5 genetic polymorphism and nephrotoxicity in tacrolimus-treated UC individuals. CYP3A5 is an enzyme responsible for the metabolism of tacrolimus and is expressed in the liver and intestinal epithelium. In this study, CYP3A5 expressers (CYP3A $5^{\star} 1$ allele carriers) are more susceptible to nephrotoxicity as compared to non-expressers $\left(\mathrm{CYP} 3 \mathrm{~A} 5^{\star} 3{ }^{*} 3\right.$ allele carriers) since they require higher doses of oral tacrolimus $(0.17 \mathrm{mg} / \mathrm{kg} /$ day $)$ and thus they need longer time to achieve the blood level of $10 \mathrm{ng} / \mathrm{ml}$, suggesting the importance of prior genotyping of CYP3A5 genetic polymorphism in tacrolimus therapy [95]. Others considered 
the development of selective drug delivery system using micro and nano-particles to reduce nephrotoxicty in experimental colitis [96] [97].

\section{Conclusion}

The EIM of IBD involves a range of renal complications including nephrolithiasis, tubulointerstitial nephritis, glomerulonephritis, amyloidosis and drug-related nephrotoxicity. Each type of renal damage seems to involve specific pathological mechanism. IBD patients are at high risk for the development of nephrolithiasis which is characterized by secondary hyperoxaluria and greatly depends on amount of resected ileum. IgAN, which the most common glomerulonephritis pattern in IBD, is associated with increased systemic IgA and mesangial disposition. On the other hand, amyloidosis is a rare EIM characterized by increased serum Amyloid A and is manifested by proteinuria and renal sufficiency. However, drug-induced nephrotoxicity appears to be more frequent among IBD patients. Given the heterogeneity of immune responses implicated in the pathogenesis of such complications, it is still difficult to predict of nature and mechanism of kidney involvement in individuals with IBD. Therefore, early detection of these kidney manifestations is of major importance, and regular monitoring of renal function in IBD patients by measuring serum creatinine and GFR could help guide therapy and eventually reduce the overall morbidity.

\section{Acknowledgements}

This work was partially supported by PHC CEDRE grant \#34974PE.

\section{Compliance with Ethical Standards}

\section{Conflict of Interest}

On behalf of all authors, the corresponding author states that there is no conflict of interest.

\section{Informed Consent}

On behalf of all authors, the corresponding author explicitly expressed their informed consent for this Review article.

Authors whose names appear on the submission have contributed sufficiently to the scientific work and therefore share collective responsibility and accountability for the content of the article. Compliance with Ethical Standards.

\section{References}

[1] Levine, J.S. and Burakoff, R. (2011). Extraintestinal Manifestations of Inflammatory Bowel Disease. Gastroenterology and Hepatology, 7, 235-241.

[2] Bamias, G., Nyce, M.R., De La Rue, S.A., et al. (2005) New Concepts in the PATHOPHYSIOLogy of Inflammatory Bowel Disease. Annals of Internal Medicine, 143, 895-904. https://doi.org/10.7326/0003-4819-143-12-200512200-00007

[3] Katsanos, K.H. and Tsianos, E.V. (2002) The Kidneys in Inflammatory Bowel Dis- 
ease. Annals of Gastroenterology, 15, 41-52.

[4] Corica, D. and Romano, C. (2016) Renal Involvement in Inflammatory Bowel Diseases. Journal of Crohn's and Colitis, 10, 226-235.

https://doi.org/10.1093/ecco-jcc/jjv138

[5] Prattis, S. and Jurjus, A. (2015) Spontaneous and Transgenic Rodent Models of Inflammatory Bowel Disease. Laboratory Animal Research, 31, 47-68. https://doi.org/10.5625/lar.2015.31.2.47

[6] Xu, X.-R., Liu, C.-Q., Feng, B.-S., et al. (2014) Dysregulation of Mucosal Immune Response in Pathogenesis of Inflammatory Bowel Disease. World Journal of Gas troenterology, 20, 3255-3264. https://doi.org/10.3748/wjg.v20.i12.3255

[7] Fuss, I.J., Heller, F., Boirivant, M., et al. (2004) Non Classical CD1d-Restricted NK T Cells That Produce IL-13 Characterize an Atypical Th2 Response in Ulcerative Colitis. Journal of Clinical Investigation, 113, 1490-1497. https://doi.org/10.1172/JCI19836

[8] Gálvez, J. (2014) Role of Th17 Cells in the Pathogenesis of Human IBD. ISRN inflammation, 928461. https://doi.org/10.1155/2014/928461

[9] Rivera-Nieves, J., Bamias, G., Vidrich, A., et al. (2003) Emergence of Perianal Fistulizing Disease in the SAMP1/YitFc Mouse, a Spontaneous Model of Chronic Ileitis. Gastroenterology, 124, 972-982. https://doi.org/10.1053/gast.2003.50148

[10] McGeachy, M.J., Bak-Jensen, K.S., Chen, Y., et al. (2007) TGF-Beta and IL-6 Drive the Production of IL-17 and IL-10 by T Cells and Restrain T(H)-17 Cell-Mediated Pathology. Nature Immunology, 8, 1390-1397. https://doi.org/10.1038/ni1539

[11] Bettelli, E., Oukka, M. and Kuchroo, V.K. (2007) T(H)-17 Cells in the Circle of Immunity and Autoimmunity. Nature Immunology, 8, 345-350.

https://doi.org/10.1038/ni0407-345

[12] Veny, M., Esteller, M., Ricart, E., et al. (2010) Late Crohn's Disease Patients Present an Increase in Peripheral Th17 Cells and Cytokine Production Compared with Early Patients. Alimentary Pharmacology \& Therapeutics, 31, 561-572. https://doi.org/10.1111/j.1365-2036.2009.04209.x

[13] Omenetti, S. and Pizarro, T.T. (2015) The Treg/Th17 Axis: A Dynamic Balance Regulated by the Gut Microbiome. Frontiers in Immunology, 6, 639. https://doi.org/10.3389/fimmu.2015.00639

[14] Ogura, Y., Bonen, D.K., Inohara, N., et al. (2001) A Frameshift Mutation in NOD2 Associated with Susceptibility to Crohn's Disease. Nature, 411, 603-606. https://doi.org/10.1038/35079114

[15] Al Nabhani, Z., Dietrich, G., Hugot, J.P., et al. (2017) Nod2: The Intestinal Gate Keeper. PLOS Pathogens, 13, e1006177. https://doi.org/10.1371/journal.ppat.1006177

[16] Jurjus, A.R., Khoury, N.N. and Reimund, J.M. (2004) Animal Models of Inflammatory Bowel Disease. Journal of Pharmacological and Toxicological Methods, 50, $81-92$.

[17] Franke, A., Balschun, T., Karlsen, T.H., et al. (2008) Sequence Variants in IL10, ARPC2 and Multiple Other Loci Contribute to Ulcerative Colitis Susceptibility. Nature Genetics, 40, 1319-1323.

[18] Müzes, G., Molnár, B., Tulassay, Z., et al. (2012) Changes of the Cytokine Profile in Inflammatory Bowel Diseases. World Journal of Gastroenterology, 18, 5848-5861.

[19] Boirivant, M., Pallone, F., Di Giacinto, C., et al. (2006) Inhibition of Smad7 with a Specific Antisense Oligonucleotide Facilitates TGF-beta1-Mediated Suppression of 
Colitis. Gastroenterology, 131, 1786-1798.

[20] Marek, A., Brodzicki, J., Liberek, A., et al. (2002) TGF-Beta (Transforming Growth Factor-Beta) in Chronic Inflammatory Conditions-A New Diagnostic and Prognostic Marker? Medical Science Monitor, 8, RA145-RA151.

[21] Kallel, L., Nijaa, N., Fatma, L.B., Rais, L., et al. (2009) Familial Cases of Glomerulonephritis Complicating Crohn's Disease. Journal of Crohn's and Colitis, 3, 125-127.

[22] Koçak, E., Köklü, S., Akbal, E., Huddam, B., et al. (2010) Development of Glomerulonephritis Early in the Course of Crohn's Disease. Inflammatory Bowel Diseases, 16, 548-549. https://doi.org/10.1002/ibd.21044

[23] Ambruzs, J.M., Walker, P.D. and Larsen, C.P. (2014) The Histopathologic Spectrum of Kidney Biopsies in Patients with Inflammatory Bowel Disease. Clinical Journal of the American Society of Nephrology, 9, 265-270. https://doi.org/10.2215/CJN.04660513

[24] Choi, J.Y., Yu, C.H., Jung, H.Y., Jung, M.K., et al. (2012) A Case of Rapidly Progressive IgA Nephropathy in a Patient with Exacerbation of Crohn's Disease. BMC Nephrology, 13, 84.

[25] Terasaka, T., Uchida, H.A., Umebayashi, R., Tsukamoto, K., Tanaka, K., Kitagawa, M., et al. (2016) The Possible Involvement of Intestine-Derived IgA1: A Case of IgA Nephropathy Associated with Crohn's Disease. BMC Nephrology, 17, 122.

[26] Wang, J., Anders, R.A., Wang, Y., et al. (2005) The Critical Role of LIGHT in Promoting Intestinal Inflammation and Crohn's Disease. The Journal of Immunology, 174, 8173-8182.

[27] Wang, J., Anders, R.A., Wu, Q., et al. (2004) Dysregulated LIGHT Expression on T Cells Mediates Intestinal Inflammation and Contributes to IgA Nephropathy. Journal of Clinical Investigation, 113, 826-835.

[28] Kiryluk, K., Li, Y., Scolari, F., Sanna-Cherchi, S. and Choi, M. (2014) Discovery of New Risk Loci for IgA Nephropathy Implicates Genes Involved in Immunity against Intestinal Pathogens. Nature Genetics, 46, 1187-1196.

[29] Onime, A., Agaba, E.I., Sun, Y., Parsons, R.B., et al. (2006) Immunoglobulin A Nephropathy Complicating Ulcerative Colitis. International Urology and Nephrology, 38, 349-353. https://doi.org/10.1007/s11255-006-0061-y

[30] Takemura, T., Okada, M., Yagi, K., Kuwajima, H. and Yanagida, H. (2002) An Adolescent with IgA Nephropathy and Crohn Disease: Pathogenetic Implications. Pediatric Nephrology, 17, 863-866.

[31] Pozzi, C., Andrulli, S., Del Vecchio, L., Melis, P., et al. (2004) Corticosteroid Effectiveness in IgA Nephropathy: Long-Term Results of a Randomized, Controlled Trial. Journal of the American Society of Nephrology, 15, 157-163.

[32] Khosroshahi, H.T. and Shoja, M.M. (2006) Tubulointerstitial Disease and Ulcerative Colitis. Nephrology Dialysis Transplantation, 21, 2340.

[33] Tokuyama, H., Wakino, S., Konishi, K., Hashiguchi, A., et al. (2010) Acute Interstitial Nephritis Associated with Ulcerative Colitis. Clinical and Experimental Nephrology, 14, 483-486. https://doi.org/10.1007/s10157-010-0294-Z

[34] Tadic, M., Grgurevic, I., Scukanec-Spoljar, M., et al. (2005) Acute Interstitial Nephritis due to Mesalazine. Nephrology, 10, 103-105.

[35] Sato, H., Umemura, K., Yamamoto, T. and Sato, H. (2017) Interstitial Nephritis Associated with Ulcerative Colitis in Monozygotic Twins. BMJ Case Reports. https://doi.org/10.1136/bcr-2016-218346

[36] Stanton, B., Caza, T., Huang, D. and Beg, M.B. (2017) Tubulointerstitial Nephritis 
as the Initial Presentation of Crohn's Disease and Successful Treatment with Infliximab. ACG Case Reports Journal, 4, e24.

[37] Herrlinger, K.R., Noftz, M.K., Fellermann, K., et al. (2002) Minimal Renal Dysfunction in Inflammatory Bowel Disease Is Related to Disease Activity But Not to 5-ASA Use. Alimentary Pharmacology \& Therapeutics, 15, 363-369. https://doi.org/10.1046/j.1365-2036.2001.00940.x

[38] Timmermans, S.A., Christiaans, M.H., Abdul-Hamid, M.A., et al. (2016) Granulomatous Interstitial Nephritis and Crohn's Disease. Clinical Kidney Journal, 9, 556-559. https://doi.org/10.1093/ckj/sfw041

[39] Heidt, J., Ooms, E.C., van der Werf, S.D. and Groeneveld, J.H. (2010) Tubulo-Interstitial Nephritis in Inflammatory Bowel Disease: Extra-Intestinal Manifestation or Drug Toxicity? Nederlands Tijdschrift Voor Geneeskunde, 154, A1647.

[40] Fraser, J.S., Muller, A.F., Smith, D.J., Newman, D.J. and Lamb, E.J. (2001) Renal Tubular Injury Is Present in Acute Inflammatory Bowel Disease Prior to the Introduction of Drug Therapy. Alimentary Pharmacology \& Therapeutics, 15, 1131-1137.

[41] Kreisel, W., Wolf, L.M., Grotz, W. and Grieshaber, M. (1996) Renal Tubular Damage: An Extraintestinal Manifestation of Chronic Inflammatory Bowel Disease. $E u-$ ropean Journal of Gastroenterology \& Hepatology, 8, 461-468.

[42] Poulou, A.C., Goumas, K.E., Dandakis, D.C., Tyrmpas, I., et al. (2006) Microproteinuria in Patients with Inflammatory Bowel Disease: Is It Associated with the Diseaseactivity or the Treatment with 5-Aminosalicylic Acid? World Journal of Gastroenterology, 12, 739-746. https://doi.org/10.3748/wjg.v12.i5.739

[43] Henry, C.B. and Duling, B.R. (2000) TNF-Alpha Increases Entry of Macromolecules into Luminal Endothelial Cell Glycocalyx. American Journal of Physiology-Heart and Circulatory Physiology, 279, H2815-H2823.

[44] Mathy, N.L., Scheuer, W., Lanzendörfer, M., et al. (2000) Interleukin-16 Stimulates the Expression and Production of Pro-Inflammatory Cytokines by Human Monocytes. Immunology, 100, 63-69.

[45] Ranganathan, P., Jayakumar, C., Santhakumar, M., et al. (2013) Netrin-1 Regulates Colon-Kidney Cross Talk through Suppression of IL-6 Function in a Mouse Model of DSS-Colitis. American Journal of Physiology-Renal Physiology, 304, F1187-F1197.

[46] Cury, D.B., Moss, A.C. and Schor, N. (2013) Nephrolithiasis in Patients with Inflammatory Bowel Disease in the Community. International Journal of Nephrology and Renovascular Disease, 6, 139-142.

[47] Fagagnini, S., Heinrich, H., Rossel, J.B., Biedermann, L., et al. (2017) Risk Factors for Gallstones and Kidney Stones in a Cohort of Patients with Inflammatory Bowel Diseases. PLOS ONE, 12, e0185193.

[48] Mukewar, S., Hall, P., Lashner, B.A., Lopez, R., et al. (2013) Risk Factors for Nephrolithiasis in Patients with Ileal Pouches. Journal of Crohn's and Colitis, 7, 70-78.

[49] Ganji-Arjenaki, M., Nasri, H. and Rafieian-Kopaei, M. (2017) Nephrolithiasis as a Common Urinary System Manifestation of Inflammatory Bowel Diseases; A Clinical Review and Meta-Analysis. Journal of Nephropathology, 6, 264-269. https://doi.org/10.15171/jnp.2017.42

[50] Nazzal, L., Puri, S. and Goldfarb, D.S. (2016) Enteric Hyperoxaluria: An Important Cause of End-Stage Kidney Disease. Nephrology Dialysis Transplantation, 3, 375-382. https://doi.org/10.1093/ndt/gfv005 
[51] Caudarella, R., Rizzoli, E., Pironi, L., et al. (1993) Renal Stone Formation in Patients with Inflammatory Bowel Disease. Scanning Microscopy, 7, 371-379.

[52] Evan, A.P., Lingeman, J.E., Worcester, E.M., Bledsoe, S.B., et al. (2010) Renal Histopathology and Crystal Deposits in Patients with Small Bowel Resection and Calcium Oxalate Stone Disease. Kidney International, 78, 310-317.

[53] Jonassen, J.A., Kohjimoto, Y., Scheid, C.R., et al. (2005) Oxalate Toxicity in Renal Cells. Urological Research, 33, 329-339. https://doi.org/10.1007/s00240-005-0485-3

[54] Knauf, F., Asplin, J.R., Granja, I., Schmidt, I.M., et al. (2013) NALP3-Mediated Inflammation Isa Principal Cause of Progressive Renal Failure in Oxalate Nephropathy. Kidney International, 84, 895-901. https://doi.org/10.1038/ki.2013.207

[55] Rodgers, A.L., Allie-Hamdulay, S., Jackson, G.E. and Sutton, R.A. (2014) Enteric Hyperoxaluria Secondary to Small Bowel Resection: Use of Computer Simulation to Characterize Urinary Risk Factors for Stone Formation and Assess Potential Treatment Protocols. Journal of Endourology, 28, 985-994.

[56] Gkentzis, A., Kimuli, M., Cartledge, J., Traxer, O. and Biyani, C.S. (2016) Urolithiasis in Inflammatory Bowel Disease and Bariatric Surgery. World Journal of Nephrology, 5, 538-546.

[57] Guardiola-Arévalo, A., Alcántara-Torres, M., Valle-Muñoz, J., et al. (2011) Amyloidosis and Crohn's Disease. Revista Espanola De Enfermedades Digestivas, 103, 268-274. https://doi.org/10.4321/S1130-01082011000500009

[58] Cabezuelo, J.B., Egea, J.P., Ramos, F., et al. (2012) Infliximab in the Treatment of Amyloidosis Secondary to Crohn's Disease. Nefrologia, 32, 385-388.

[59] Powell-Tuck, J. (1986) Protein Metabolism in Inflammatory Bowel Disease. Gut, 27, 67-71. https://doi.org/10.1136/gut.27.Suppl_1.67

[60] Dinarello, C.A., Simon, A. and van der Meer, J. (2012) Treating Inflammation by Blocking Interleukin-1 in a Broad Spectrum of Diseases. Nature Reviews Drug Discovery, 11, 633-652. https://doi.org/10.1038/nrd3800

[61] Topaloglu, R., Batu, E.D., Orhan, D., Ozen, S. and Besbas, N. (2015) Anti-Interleukin 1 Treatment in Secondary Renal Amyloidosis Associated with Autoinflammatory Diseases. Pediatric Rheumatology Online Journal, 13, 149. https://doi.org/10.1186/1546-0096-13-S1-P149

[62] Azad Khan, A.K., Piris, J. and Truelove, S.C. (1977) An Experiment to Determine the Active Therapeutic Moiety of Sulphasalazine. The Lancet, 2, 892-895. https://doi.org/10.1016/S0140-6736(77)90831-5

[63] Rousseaux, C., Lefebvre, B., Dubuquoy, L., Lefebvre, P., et al. (2005) Intestinal Antiinflammatory Effect of 5-Aminosalicylic Acid Is Dependent on Peroxisome Proliferator-Activated Receptor-Gamma. The Journal of Experimental Medicine, 201, 1205-1215. https://doi.org/10.1084/jem.20041948

[64] Iacucci, M., de Silva, S. and Ghosh, S. (2010) Mesalazine in Inflammatory Bowel Disease: A Trendy Topic Once Again? Canadian Journal of Gastroenterology, 24, 127-133. https://doi.org/10.1155/2010/586092

[65] World, M.J., Stevens, P.E., Ashton, M.A. and Rainford, D.J. (1996) Mesalazine-Associated Interstitial Nephritis. Nephrology Dialysis Transplantation, 11, 614-621. https://doi.org/10.1093/oxfordjournals.ndt.a027349

[66] Ransford, R.A. and Langman, M.J. (2002) Sulphasalazine and Mesalazine: Serious Adverse Reactions Re-Evaluated on the Basis of Suspected Adverse Reaction Reports to the Committee on Safety of Medicines. Gut, 51, 536-539. https://doi.org/10.1136/gut.51.4.536 
[67] Muller, A.F., Stevens, P.E., McIntyre, A.S., Ellison, H. and Logan, R.F. (2005) Experience of 5-Aminosalicylate Nephrotoxicity in the United Kingdom. Alimentary Pharmacology \& Therapeutics, 21, 1217-1224. https://doi.org/10.1111/j.1365-2036.2005.02462.x

[68] Schreiber, S., Hämling, J., Zehnter, E., Howaldt, S., Daerr, W., et al. (1997) Renal Tubular Dysfunction in Patients with Inflammatory Bowel Disease Treated with Aminosalicylate. Gut, 40, 761-766. https://doi.org/10.1136/gut.40.6.761

[69] Corrigan, G. and Stevens, P.E. (2000) Review Article: Interstitial Nephritis Associated with the Use of Mesalazine in Inflammatory Bowel Disease. Alimentary Pharmacology \& Therapeutics, 14, 1-6. https://doi.org/10.1046/j.1365-2036.2000.00683.x

[70] Cunliffe, R.N. and Scott, B.B. (2002) Review Article: Monitoring for Drug Side-Effects in Inflammatory Bowel Disease. Alimentary Pharmacology \& Therapeutics, 16, 647-662. https://doi.org/10.1046/j.1365-2036.2002.01216.x

[71] Verschueren, P., Lensen, F., Lerut, E., Claes, K., et al. (2003) Benefit of Anti-TNFalpha Treatment for Nephrotic Syndrome in a Patient with Juvenile Inflammatory Bowel Disease Associated Spondyloarthropathy Complicated with Amyloidosis and Glomerulonephritis. Annals of the Rheumatic Diseases, 62, 368-369. https://doi.org/10.1136/ard.62.4.368

[72] Sakellariou, G.T., Vounotrypidis, P. and Berberidis, C. (2007) Infliximab Treatment in Two Patients with Psoriatic Arthritis and Secondary IgA Nephropay. Clinical Rheumatology, 26, 1132-1133. https://doi.org/10.1007/s10067-006-0422-Z

[73] Sokumbi, O., Wetter, D.A., Makol, A. and Warrington, K.J. (2012) Vasculitis Associated with Tumor Necrosis Factor- $\alpha$ Inhibitors. Mayo Clinic Proceedings, 87, 739-745. https://doi.org/10.1016/j.mayocp.2012.04.011

[74] Chin, G., Luxton, G. and Harvey, J.M. (2005) Infliximab and Nephrotic Syndrome. Nephrology Dialysis Transplantation, 20, 2824-2826.

https://doi.org/10.1093/ndt/gfi180

[75] den Broeder, A.A., Assmann, K.J., van Riel, P.L. and Wetzels, J.F. (2003) Nephrotic Syndrome as a Complication of Anti-TNFalpha in a Patient with Rheumatoid Arthritis. The Netherlands Journal of Medicine, 61, 137-141.

[76] Villemaire, M., Cartier, J.C., Mathieu, N., Maurizi, J., et al. (2014) Renal Sarcoid-Like Granulomatosis during Anti-TNF Therapy. Kidney International, 86, 215. https://doi.org/10.1038/ki.2013.452

[77] Yoo, Y.J., Chung, S.Y., Gu, D.H., Ko, G.J., et al. (2014) A Case of Late Onset-Acute Tubulointerstitial Nephritis with Infliximab and Mesalazine Treatment in a Patient with Crohn's Disease. The Korean Journal of Gastroenterology, 63, 308-312. https://doi.org/10.4166/kjg.2014.63.5.308

[78] Dumitrescu, G., Dahan, K., Treton, X., Corcos, O., et al. (2015) Nephrotic Syndrome after Infliximab Treatment in a Patient with Ulcerative Colitis. Journal of Gastrointestinal and Liver Diseases, 24, 249-251.

[79] Charles, P.J., Smeenk, R.J., De Jong, J., Feldmann, M. and Maini, R.N. (2000) Assessment of Antibodies to Double-Stranded DNA Induced in Rheumatoid Arthritis Patients Following Treatment with Infliximab, a Monoclonal Antibody to Tumor Necrosis Factor Alpha: Findings in Open-Label and Randomized Placebo-Controlled Trials. Arthritis \& Rheumatology, 43, 2383-2390. https://doi.org/10.1002/1529-0131(200011)43:11<2383::AID-ANR2>3.0.CO;2-D

[80] Ziolkowska, M. and Maslinski, W. (2003) Laboratory Changes on Anti-Tumor Ne- 
crosis Factor Treatment in Rheumatoid Arthritis. Current Opinion in Rheumatology, 15, 267-273. https://doi.org/10.1097/00002281-200305000-00014

[81] English, J., Evan, A., Houghton, D.C. and Bennett, W.M. (1987) Cyclosporine-Induced Acute Renal Dysfunction in the Rat. Evidence of Arteriolar Vasoconstriction with Preservation of Tubular Function. Transplantation, 44, 135-141. https://doi.org/10.1097/00007890-198707000-00027

[82] Kon, V., Sugiura, M., Inagami, T., Harvie, B.R., et al. (1990) Role of Endothelin in Cyclosporine-Induced Glomerular Dysfunction. Kidney International, 37, 1487-1491. https://doi.org/10.1038/ki.1990.139

[83] Bobadilla, N.A. and Gamba, G. (2007) New Insights into the Pathophysiology of Cyclosporine Nephrotoxicity: A Role of Aldosterone. American Journal of Physiology-Renal Physiology, 293, F2-F9. https://doi.org/10.1152/ajprenal.00072.2007

[84] Snanoudj, R., Royal, V., Elie, C., Rabant, M., et al. (2011) Specificity of Histological Markers of Long-Term CNI Nephrotoxicity in Kidney-Transplant Recipients under Low-Dose Cyclosporine Therapy. American Journal of Transplantation, 11, 2635-2646. https://doi.org/10.1111/j.1600-6143.2011.03718.x

[85] Shang, M.H., Yuan, W.J., Zhang, S.J., Fan, Y. and Zhang, Z. (2008) Intrarenal Activation of Renin Angiotensin System in the Development of Cyclosporine a Induced Chronic Nephrotoxicity. Chinese Medical Journal, 121, 983-988.

[86] Sereno, J., Rodrigues-Santos, P., Vala, H., Rocha-Pereira, P., Alves, R., et al. (2014) Transition from Cyclosporine-Induced Renal Dysfunction to Nephrotoxicity in an in Vivo Rat Model. International Journal of Molecular Sciences, 15, 8979-8997. https://doi.org/10.3390/ijms15058979

[87] Sandborn, W.J. (1995) Cyclosporine Therapy for Inflammatory Bowel Disease: Definitive Answers and Remaining Questions. Gastroenterology, 109, 1001-1003. https://doi.org/10.1016/0016-5085(95)90413-1

[88] Feagan, B.G., McDonald, J.W., Rochon, J., Laupacis, A., et al. (1994) Low-Dose Cyclosporine for the Treatment of Crohn's Disease. The Canadian Crohn's Relapse Prevention Trial Investigators. The New England Journal of Medicine, 330, 1846-1851. https://doi.org/10.1056/NEJM199406303302602

[89] Sandborn, W.J., Tremaine, W.J. and Lawson, G.M. (1996) Clinical Response Does Not Correlate with Intestinal or Blood Cyclosporine Concentrations in Patients with Crohn's Disease Treated with High-Dose Oral Cyclosporine. The American Journal of Gastroenterology, 91, 37-43.

[90] Oikonomou, K.A., Kapsoritakis, A.N., Stefanidis, I. and Potamianos, S.P. (2011) Drug-Induced Nephrotoxicity in Inflammatory Bowel Disease. Nephron Clinical Practice, 119, c89-c94. https://doi.org/10.1159/000326682

[91] Ogata, H., Matsui, T., Nakamura, M., Iida, M., et al. (2006) A Randomised Dose Finding Study of Oral Tacrolimus (FK506) Therapy in Refractory Ulcerative Colitis. Gut, 55, 1255-1262. https://doi.org/10.1136/gut.2005.081794

[92] Wingard, J.R., Nash, R.A., Przepiorka, D., Klein, J.L., et al. (1998) Relationship of Tacrolimus (FK506) Whole Blood Concentrations and Efficacy and Safety after HLA-Identical Sibling Bone Marrow Transplantation. Biology of Blood and Marrow Transplantation, 4, 157-163. https://doi.org/10.1016/S1083-8791(98)50005-5

[93] Sandborn, W.J., Present, D.H., Isaacs, K.L., Wolf, D.C., et al. (2003) Tacrolimus for the Treatment of Fistulas in Patients with Crohn's Disease: A Randomized, Placebo-Controlled Trial. Gastroenterology, 125, 380-388. https://doi.org/10.1016/S0016-5085(03)00877-1 
[94] Hosoi, K., Arai, K., Matsuoka, K., Shimizu, H., et al. (2017) Prolonged Tacrolimus for Pediatric Gastrointestinal Disorder: Double-Edged Sword? Pediatrics International, 59, 588-592. https://doi.org/10.1111/ped.13211

[95] Asada, A., Bamba, S., Morita, Y., Takahashi, K., et al. (2017) The Effect of CYP3A5 Genetic Polymorphisms on Adverse Events in Patients with Ulcerative Colitis Treated with Tacrolimus. Digestive and Liver Disease, 49, 24-28. https://doi.org/10.1016/j.dld.2016.09.008

[96] Meissner, Y., Pellequer, Y. and Lamprecht, A. (2006) Nanoparticles in Inflammatory Bowel Disease: Particle Targeting versus $\mathrm{pH}$-Sensitive Delivery. International Journal of Pharmaceutics, 316, 138-143. https://doi.org/10.1016/j.ijpharm.2006.01.032

[97] Lamprecht, A., Yamamoto, H., Ubrich, N., Takeuchi, H., et al. (2005) FK506 Microparticles Mitigate Experimental Colitis with Minor Renal Calcineurin Suppression. Pharmaceutical Research, 22, 193-199.

https://doi.org/10.1007/s11095-004-1186-2 